\title{
GIS, integrated solution, for efficient administration of Hunedoara County
}

\author{
Eugenia Jornea ${ }^{1}$, Lucian Lupu-Dima ${ }^{1}$, and Eduard Edelhauser ${ }^{1, *}$ \\ ${ }^{1}$ University of Petroșani, 20 Universității Street, 20, România
}

\begin{abstract}
The local administration became in Romania a very important element for development. The requirements for the management activity in administration has changed as compared with what happened 10 years ago. The new issues raised by the complex needs and not always concurrent of the population, business agents and the trends in regional development are increasingly difficult to be managed with traditional tools. The adaptability and the scalability of Geographical Information Systems, represent an opportunity of the responsible from top management of the local administration that cannot be ignored. The intent of this study is to present a model to be followed for the use of GIS in management of the Hunedoara County Council.This model can change, the meaning of the idea of management at the local administration level by using the foresight as a support for decision making, through the access to the current and complete information and through the involvement of the GIS beneficiaries in providing updated data and in their transformation from simple beneficiaries of the management of the local administration in partners or even intervenients in the decisional process.
\end{abstract}

\section{Motivation}

Based on the statement made by Jack Dangermond of ESRI, which implies that: "The application of GIS is limited only by the imagination of those who use it", we can let ourselves carried away by thoughts and ideas and to build almost any system.

Romanian territory is organized into territorial-administrative units: county, municipality, city, town, township and village. Bucharest the capital city of Romaniais organized by sectors. The county is lead under the laws of Romania, in a two-headed way, by the County Council and by the Government, through Prefecture. The County Council has the most important role and it also has the most appropriate tools for ensuring the proper administration of existing resources, the coordination of the various subordinate entities or of those with which it collaborates and also ofthe creation of the conditions of the materialization of the favourable opportunities for the county.

This paper work aims to analyse the possibilities of developing and to recommend a GIS solution for Hunedoara County, solution that can change the philosophy of the local and even of national administration. There are premises for such a system to simplify the

\footnotetext{
* Corresponding author: eduardedelhauser@upet.ro
} 
decision making, to create the capacity of foresight and to generate resources for the system to be self-sustainable.

\section{An evaluation of present}

This evaluation aims to briefly present Hunedoara county and by that to suggest the complexity of a GIS for this county. A succinct look over the users of GIS in local administration or over GIS achievements in domains that can and should be used in the proposed systems proves the uniqueness of such GIS for Hunedoara county.

\subsection{About Hunedoara, size, organization, institutions, resources}

According to the public information displayed at National Institute of Statistics [3], Hunedoara county, situated in the central western part of Romania, represents $2.96 \%$ from Romanian territory, with a surface of 7063 square kilometres. In terms of administrative territory, the country includes 14 cities from which 7 municipalities and 55 communes with 457 villages.

In the monograph of Hunedoara [4] County we can find the information according with which the GDP of the county, represents $1.82 \%$ of the national GDP. One can also find in here interesting information regarding the structuring of economic agents by the number of employees.

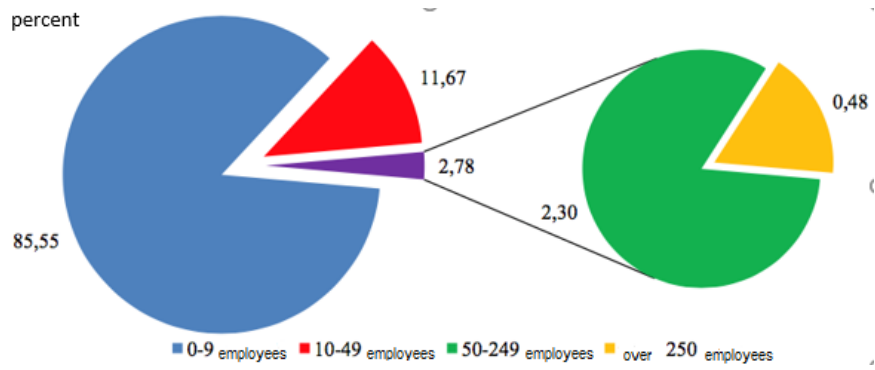

Fig. 1. The structure of active local units on size classes after the number of employees 2012 [4].

Note that Hunedoara is among the most important counties in terms of mineral resources exploitation, having three specialized companies: Energetic Complex Hunedoara, Min Vest Deva and National Society of Mine Closing Jiu Valley.

Analysing the public information offered by Hunedoara County Council [5], it is noticed that it has subordinated 16 institutions. The County Council is the majority shareholder of the two companies that provide alimentation with drinking water services, APA PROD S.A. Deva (with the administration of about $1000 \mathrm{~km}$ network) and ApaServ Jiu Valley S.A. Petrosani (with the administration of approximately $600 \mathrm{~km}$ network).

This brief presentation of the defining elements of the country has a goal the support of the affirmation that claims Hunedoara to be a county with great diversity and with special and complex needs.

\subsection{Relevant examples of the use of GIS as presented in this paper}

Following the analysis made by us we concluded that using GIS in administration is quite widespread in Romania nowadays. It can be stated, based on public information that Timisoara City Hall is the pioneer of public local administration, being the first institution of its kind, which implemented a GIS since 1998, the system becoming operational after 
five years and an expense of \$ 1.2/inhabitant [6]. Oradea also started in 2003 the implementation of a GIS now according to public information the vectorization of the streets structure being resolved [7]. GIS is used in many localities such as: Bistrita, SatuMare, Iasi, Tecuci, Resita, Focsani, Cluj, Sibiu, Bucuresti. Utility companies have switched to using GIS in the current work, an example being Apa Nova Bucharest, which has become an example of best practice. Another example is Aquatim Timisoara that made an extra step, by extending the domain of activity of the company, achieving in 2013 from the ANCPI the right to perform specialized work in the field of cadastre, geodesy and cartography in Class $\mathrm{S}$, authorization valid for 5 years.

Companies of the kind like those from: Braşov, Sibiu, Piteşti, Iaşi, Botoşani, Giurgiu, Alexandria can be mention as examples, with different GIS dimensions. In Hunedoara county one can find a GIS of green areas implemented in Petrosani and other 2 GIS of 2 societies of water and sewage.

According to ESRI Romania [8], in USA, over $80 \%$ from the administrative structures, from every level use GIS or to be more exact ESRI technology. The ESRI has created a model for the Local Administration as shown in figure 2.

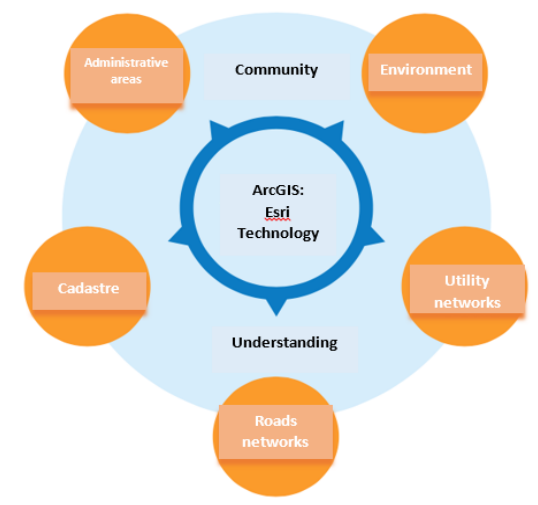

Fig. 2. Graphical model of GIS usage in Local Administration [8]

The model referred to, has the system focused on the economic development of the aria and on the citizen, as a source of information and as active participant in decision making. The system has a component for emergency situations, public safety, health and social services, administration of the terrains and cadastre, transport and utilities.

On the international level, there is enough evidence of the use of GIS as presented in this paper. A useful example for the component of the roads infrastructure can be found at Cepni and Aslan [9], tackled, by using GIS, aspects linked to the causality of accidents in traffic, approaching this topic of growing importance, in a complex mode that took into consideration aspects linked to technical component of vehicles, of road infrastructure yet without ignoring the psychological and socio economic component of the traffic participants. By using tools offered by GIS they modelled and designed risks maps, showing the distribution of accidents for 2015 (fig. 3). By using the analysis of collected information, the researchers show that when the routes, either that we talk about intersections or not, which represent high danger, are subjected to studies of geometric investigation, the number of fatalities is reduced. The use of such analysis system would contribute to the achievement of the National Strategy for Road Safety targets for the period 2015-2020, published by the Ministry of Environment [11]. 


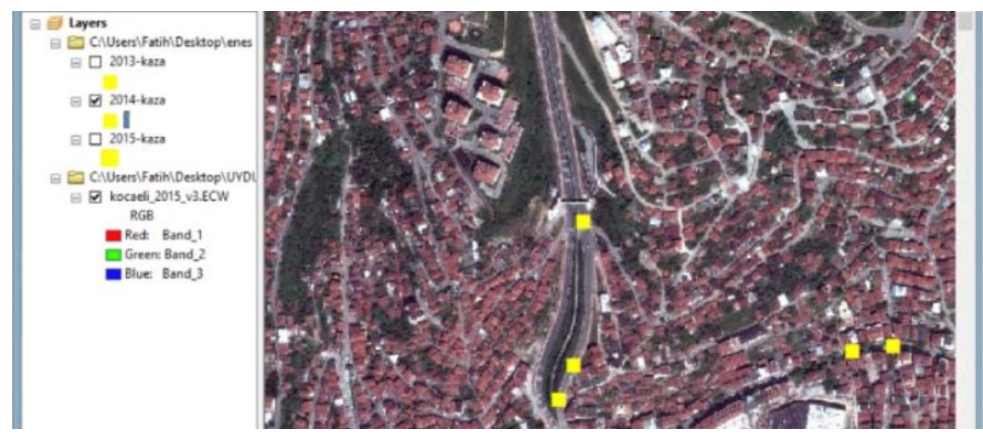

Fig. 3. Accident at the road section. [8]

Directly related with the politics of local and regional development another relevant example is found in the thesis written by Sara Meerow and Joshua P. Newell [10] that shows how, by using GIS, solution for spatial planning for multifunctional green infrastructure. Using for the study Detroit city, it is proved that the planning of the green infrastructure moves from the inventory and keeping of record stage (situation found in green GIS from the most Romanian localities) to the one in which "green" is analysed, designed, made, maintained and developed by using the concept of Green Infrastructure Spatial Planning (GISP) model, a GIS-based multi-criteria approach that integrates six benefits: storm water management; social vulnerability; green space; air quality; urban heat island amelioration; and landscape connectivity. [10]

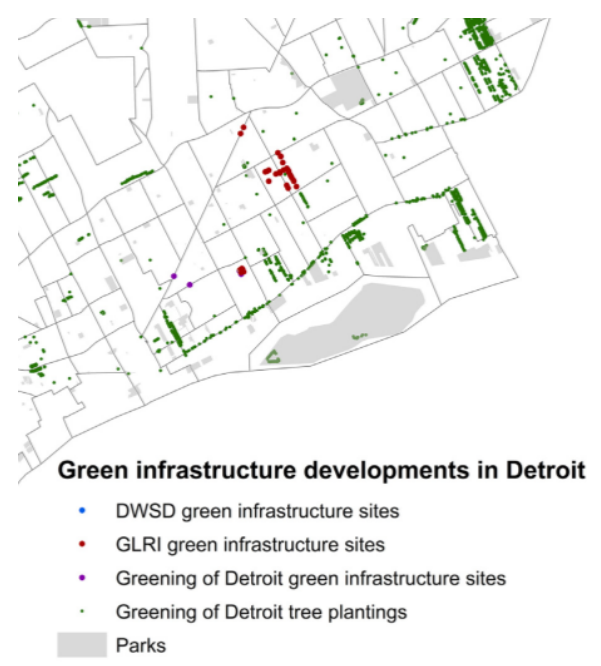

Fig. 4. Locations of major green infrastructure projects across the city of Detroit, [10]

There are many examples, but it is not the case to enumerate them all, because the goal is reached right now, the fact, that there are no limits in using GIS in this area of interest, being obvious.

\section{GIS at Hunedoara County level}

The difference between the classic of the attainment and of the implementation of a GIS and our preposition is that, that in this case the goal is the generation of the course of changing of the way a county is managed, involving all the actors that activate on the 
Territory of Hunedoara County, either that they are localized in the county, or they are just in transit interact and this fact exceeds their choice and also offers to the decision making staff from the County Council the power of analysis and of processing of a GIS.

The efficiency of the administration becomes a result and ceases to be a purpose. A system, a mechanism, that makes this choice friendlier with themselves and with the environment of the county, that maximizes the strength and diminishes their weakness generated by inevitable divergent interests of the actors, previously mentioned, provides a natural increase of the efficiency of the managerial acts of the leaders of the county.

The fact that all those who have access to such system, have not only the status of beneficiary but also of information provider, system has a dynamic character, with permanent updated information and also competitive verified by users.

\subsection{Proposition regarding the usage of GIS at Hunedoara County level}

By using public information available now, some presented at the beginning of this paper, we have created by using ArcMap, a structure of layers to support, visually at this moment, this kind of project. We have chosen to use as layers, for the picture in figure 5, localities of the county, highlighting the localities where the population is over 2000 inhabitants suggestively, roads, railways, lakes, rivers, administrative territorial units. For the base layer "Corine Land Cover Europe 2006" was used.

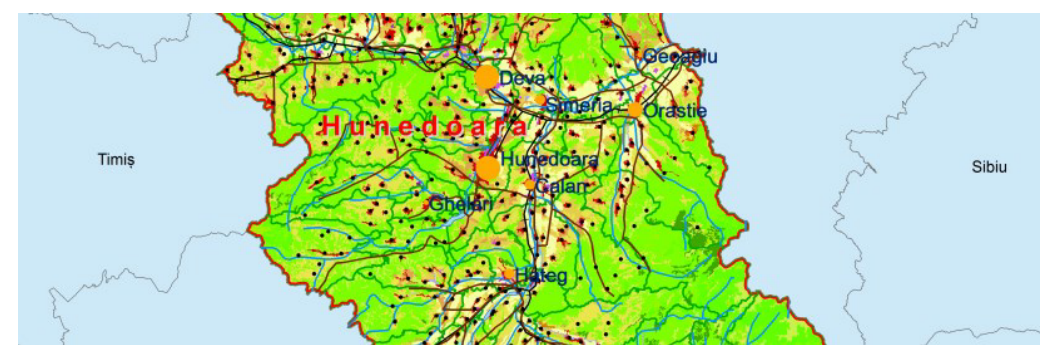

Fig. 5. Hunedoara County (a part) with structure of layers.

In our opinion, such system is necessary to be implemented at the Hunedoara County Council, the argument being linked to what we showed at the beginning of this paper, regarding territorial organization of Romania, but also in direct connection with the structure of institutions subordinated to the Council and with unlimited life.

The specificity of such a project requires, in our view, the achievement of a correct staging of implementation. After getting over the first stage, that is already accomplished, the scope being "Hunedoara GIS", and that preceded the building of the Management System of Database, which is needed for the construction of the structure of involved actors. They will be structured after their role, contribution, commitment, benefits, constrains as follows:

- Project Leader - Hunedoara County Council, coordinator and system manager, the guarantor of the fulfilment of project objectives;

- Lead partners - city and town halls of all the localities of the county, state and private institutions, data providers and requirements from the design stage, throughout the operating of the system, direct beneficiaries of the system;

- Coercion partners - state entities, generating legal constraints and not only, who will be informed by the implementation of the system and requested to generate requirements, if the case;

- Volunteer partners - selected through public consultation, potential beneficiaries and generators of requirements in exhaustive completion. 
This structure of partners will create a model of the project management that will be kept in the functioning time of the system, and then being treated as a project in continuous progress. Following the collecting of the requirements by GIS, a system of database management is designed, capable of satisfying all the requirements and at the same time of allowing the implementation of new requirements, in the context of continuous adding of information. It is anticipated that the acquirement of special data to be done in all eligible ways, taking into consideration as main channel, the automatic one, using remote sensing.

Regarding GIS structure, our opinion is that it will be constituted as a package of many GIS, in an arborescent style, those GIS coming to coalesce. This approach is unimaginable, as it is in fact the innovative element. For example, there will be GIS of localities, green, urban, of road signs, of cemeteries, which will be extended in plan from one locality to the other and they will have gaps of information, where the layer is not applicable. Although it is premature to appreciate that at this moment, we estimate that the number of layers will exceed 30.GIS of the institutions will cover the ascribed zone, as for example with APA PROD S.A. Deva and Apa Serv Valea Jiului S.A. Petroşani, which have identical domains of activity but different areas. Practically one can speak of one GIS with two subdivisions. The same way, the insertion of information and the requests from the operators of utilities, telecommunications, from the Road Company, Road Authority, Inspectorate for Emergency Situations, state or private institutions are approached.

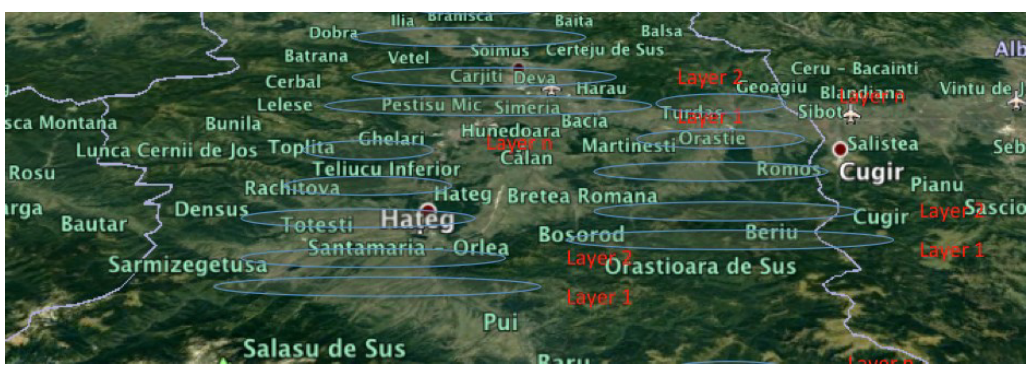

Fig. 6. The visual model of the construction of layers as mini interconnected GIS (a Google Earth Pro capture was used).

Tools with which data are collected continue to be created and the data are uploaded into DBMS. Permanent verifications are conducted to identify potential errors and to permit the correction of possible discrepancies. The evaluation at this stage has stated a scope and some potential adjustments of DBMS, considering that in fact at this moment designing of DBMS is to be verified. Following the processing of data,outputs from the system are obtained such as maps and reports. All of these are built to meet the requirements of the partners from the project. At the same time, the analysis of the interdependencies from the requirements and of complementary factors from these, can conduct to results that exceed the expectations of the beneficiaries of the system.

\subsection{Advantages of using GIS in the county}

The implementation of GIS in the entire Hunedoara County, in the proposed form from the presented paper, would bring positive immediate results on many levels. At the level of the localities, local administration benefits of complete and permanently updated information, this way all that means the attribute of this administrative structure, from taxes to investment and development being tracked with ease. At the centralized level of the county the capacity of unitary administration of its resources is increased, by harmonious correlation of the development requests. At the level of direct interaction with the government, is made available for it, by means of prefecture, all the necessary elements. At 
the level of institutions for which the information of the kind speeds the reaction, such as Emergency Situations Inspectorate or those medical infrastructure, or those that protect the citizens. At the level of economic agents, which through rapid access at spatial information can design in the future, their investment plans, with a much smaller margin of error. At the level of population to which, such a tool, offers unexpected resources of interaction with entities of the county, but also means of information facile and current.

The most important advantage, that in fact is also the strong argument for the creation of such a system for Hunedoara county is the streamlining of the county administration, by means of all those shown previously, but also through the capacity of assimilation of all the applicable standards in the administration, management or related fields. GIS for Hunedoara county is a system that will be integrated with the informatic system of the County Council, the work interface with the management structure being ensured through a BI.

\subsection{The possibility of extending and interconnecting the resulted system}

Each of the benefits that the existence of GIS brings to Hunedoara county, can be detailed. Because from the technical point of view, the open character of such a system represents a central advantage, we choose to show it in detailed. A GIS of this kind, structured in the proposed form, offers a benefit we can call "gold benefit" since it can very easily interconnect with all kind of system, external to the county, either that it is about one of the neighbouring county or about a national one, in accordance with the INSPIRE [2] requirements. Actually, channels of informational connection adequate for almost any kind of situation are provided.

This idea started from the premise that at the county level all the needs will be covered. To support the open character of the system, we show some of the possibilities of extension and of interconnection:

- extension of the model to the level of the adjacent counties for the area of development from which Hunedoara is part, these managing to work unitary based on the same logic;

- interconnection with SNEP (ghiseul.ro), with the scope of the improvement of its performances;

- interconnection with the Unique Registry of Transparency of Interests, becoming a platform for the services of E-Consultancy, E-Debate or other actions of the Registry.

Each extension or interconnection will be constituted in exchange channels of information capable of feeding the system and to allow for it to serve better to the scope of the streamlining of the administration of Hunedoara county.

\section{Conclusions}

The idea of creating a GIS for a county, for Hunedoara county, is not a spectacular one and it can even be considered as a normality. The approach proposed in this paper is the innovative element and generator of change. Even if the idea is presented as a concept, it is feasible and sustainable.

This generate some elements of novelty:

- GIS as a complex structure of GISs;

- Principle of application of project management, in the implementation phase, based on the balancing of the roles of partners and on keeping of this principle during the functioning of the system;

- The use of the forecast as a support of the decision through the access to the current and to as complete as possible information. 
Through this paper we have tried to make the first step, in the designing and implementing of what we believe to be the most important project of Hunedoara County. The suggested system exceeds the requirements of INSPIRE, because while the requirements of INSIRE are applied to the public institution, GIS for Hunedoara, brings together the public institutions, business, civil society and population and keeps intact the rigors of INSPIRE. The next step is the development of a complex study able to evaluate the existent and actual situation not only at the preparedness level of the territorial administrative units for the GIS implementation, but also in terms of their expectations from a GIS, namely the willingness to be an active part in the implementation process. This will represent, in fact, the premise from which a GIS implementation will start. The offered benefits, the lack of limits of development and expansion, are advantages that exponentially multiply. Premises for changing of the paradigm of management of Hunedoara County will be created.

The system can become an indispensable tool for each decision in the functioning of the Hunedoara County Council, allowing the propagation of these decisions and ensuring a better applicability for them and a control of their fulfilment.

The statement from the paper that such a system comes to be self-sustainable is substantiated by the way the information is to be available to the beneficiaries, under subscription regime or by using of the kind "pay for view". A GIS of such amplitude, after starting being used, comes to have a perpetual use, ensuring for itself the needed financial resources for the maintenance and for the further development, from any point of view.

\section{References}

1. INSSE - http://statistici.insse.ro/shop/?page=tempo3\&lang=ro\&ind=ADM101A (2016)

2. Parlamentul European, DIRECTIVA 2007/2/CE/14.03.2007, http://ogp.gov.ro/wpcontent/uploads/2013/10/Directiva-INSPIRE.pdf

3. INSSEHd - http://www.hunedoara.insse.ro/main.php (2016)

4. BNR - MonografieJudetul Hunedoara, 26.06.2014, http://www.bnr.ro/DocumentInformation.aspx?idInfoClass=13567\&idDocument=17760\&direct $\underline{\text { Link}=1}$ (2016)

5. CJHd - http://www.cjhunedoara.ro (2016)

6. PrimăriaMunicipiuluiTimișoara - www.primariatm.ro (2016)

7. PrimăriaMunicipiului Oradea, www.oradea.ro (2016)

8. ESRI România - www.esri.ro (2016)

9. S. Cepni, M., O. Arslan,A International Scientific Conference On Applied Sciences - Antalya, Turkey (2016)

10. Sara Meerow, Joshua P. Newell, Landscape and Urban Planning, Volume 159, http://www.sciencedirect.com/science/article/pii/S0169204616302250 (2017)

11. MinisterulMediului - http://www.mmediu.ro/articol/strategia-nationala-pentru-siguranta-rutierapentru-perioada-2015-2020-si-a-programului-de-actiuni-prioritare-pe-perioada-2015-2020-deimplementare-a-strategiei-nationala-pentru-siguranta-rutiera-pentru-perioada-2015-2020/849, 2016) 